salmonellas from bulk eggs produced by five of the 11 farms surveyed; they failed to grow any organisms from 1000 shell eggs examined. ${ }^{8}$ More detailed information is undoubtedly required about the distribution of infection among flocks, the incidence of infected birds within flocks, the frequency with which infected birds lay infected eggs, and the numbers of salmonella organisms present in such eggs.

Among possible control methods, recent research has shown that irradiating eggs is feasible, but at present it is illegal to sell irradiated food ín Britain. In the immediate future, however, the use of irradiation to sterilise poultry feedstuffs offers greater promise but could only be complementary to establishing infection free breeding stocks.

Given the current level of salmonellosis in Britain, whether poultry borne or egg borne, it can only be in the long term interests of the poultry industry as a whole, as well as of the consumer, that these objectives are realised. Meanwhile, the recommendations issued by the United Kingdom departments of health, and re-emphasised last week, advising against the consumption of foods to be served cold with raw egg as an ingredient need to be followed, along with the maintenance of proper standards of kitchen hygiene and good temperature control throughout food preparation.

Consultant Epidemiologist, J C M SHARP

Communicable Diseases (Scotland) Unit,

Ruchill Hospital,

Glasgow G20 9NB

1 Editorial. Salmonella enteritidis phage type 4: chicken and egg. Lancet 1988;ii:720-2.

2 Perales I, Audicana A. Salmonella enteritidis and eggs. Lancet 1988;ii: 1133.

St Louis ME, Morse DL, Potter ME, et al. The emergence of grade A eggs as a major source of Salmonella enteritidis infections. FAMA 1988;259:2103-7.

4 O'Brien JDP. Salmonella enteritidis infections in broiler chickens. Veterinary Record 1988;122:214.

Lister SA. Salmonella enteritidis infection in broilers and broiler breeders. Veterinary Record 1988;123:350.

6 Hopper SA, Mawer SL. Salmonella enteritidis in poultry. Veterinary Record 1988;123:351.

7 Humphrey TJ, Mead GC, Rowe B. Poultry meat as a source of human salmonellosis in England and Wales. Epidemiology and Infection 1988;100:175-84

8 Chapman PA, Rhodes P, Rylands W. Salmonella typhimurium phage type 141 infections in Sheffield during 1984 and 1985: association with hens' eggs. Epidemiology and Infection 1988;101:75-82.

9 Devine E, Finnie BG. Outbreak of egg-borne salmonella "food poisoning". Communicable Diseases Scotland Weekly Report 1988;22 No 11:5-6.

10 Kohli HS, MacLeod M, Ross G, Armstrong J, Stevenson J. An outbreak of salmonellosis in Clydebank due to contaminated mayonnaise. Communicable Disease Scotland Weekly Report

11 Coyle EF, Palmer SR, Ribeiro CD, et al. Salmonella enteritidis phage type 4 infection: association with hens' eggs. Lancet 1988;ii:1295-6.

\title{
Government must act on community care
}

\author{
An agency to oversee local authorities might be the best option
}

It is now nine months since the publication of the Griffiths report on community care ${ }^{12}$-ample time for the government to consider the proposals. Yet still it has not responded. A recent survey by the King's Fund Institute found widespread consensus among district managers in the health service and social service directors that a response was urgently required and the time overdue for a change in government policy. ${ }^{3}$ Clearly central government should set objectives, establish a framework for planning, and supervise the implementation of local plans. Griffiths suggested that this task should be spearheaded by a minister with responsibility for community care.

Enthusiastic debate followed the publication of the Griffiths report, and overall it has received increasingly positive support. There is agreement on the report's three key principles: targeting resources at the most needy, providing a suitable domestic environment, and giving more voice and more choice to consumers and their families. Most of Griffiths's five recommendations for achieving these objectives have also been applauded. One of the most attractive of these is a system of care management in which managers hold budgets and have clearly defined responsibilities to provide a service to a group of clients. There was support too for new methods of financing through a specific community care grant; for all public funds for residential care to be channelled through a single agency; for promoting greater diversity of provision by the statutory, private, and voluntary sectors; for joint training across agencies; and for developing generic "hands on" community carers to provide personal care. Overall, the Griffiths principles provide a strategy for creating order out of the current chaos in community care.

The government's lengthy silence on the report is widely attributed to one sticking point - the recommendation that local authorities should become the "lead agency" responsible for community care. This one notion alone accounts for the King's Fund Institute's finding that nine out of 10 directors of local authority social services were in favour of the proposals in contrast to less than half $(46 \%)$ of district general managers.
Opposition within professional organisations has largely centred on this point and is less about losing health service resources to local authorities than about a deep scepticism as to the commitment, capability, and effectiveness of some social services departments. Some authorities have committed themselves to caring for elderly people and people with a mental handicap or physical disability, but the widespread failure of local government to recognise the plight of people who are chronically mentally ill, a politically unattractive cause, has aroused enormous anxiety. At government level, while David Mellor and Edwina Currie are broadly in favour of Griffiths, Kenneth Clarke is said to be unconvinced. Could the proposals be implemented in such a way that the potential disadvantages of local authorities taking the key role are overcome?

There exist practical proposals for a way forward. The Association of Directors of Social Services has proposed a community care development agency to audit the available funds from all services, oversee the development of plans, and monitor their initial implementation. Such an agency could ensure that budgets were truly "ring fenced" and that local plans were acceptable. It might be dissolved once a smooth transition to local government had been effected. The attraction of this solution to the government is that it provides a model for central government to gain greater control over other local government services.

A more radical solution would be to combine the community health services and community care parts of priority care services (currently within health authorities) with family practitioner services and social services departments to create one primary health care authority. This could fit in with the government's expressed intention of unfettering the short stay hospital sector and developing the internal market among health authorities. It has the advantage of combining those primary care professionals who should work closely together, and the independent contractor status of general practitioners fits in well with a primary care authority purchasing 
community care services flexibly from the statutory, voluntary, and private sectors. If the purchasing power of these new authorities were to extend to short stay hospital services they could prove a potent force for reshaping health services to suit local population needs.

This radical solution could, however, have a profoundly depressing effect on the morale of a health service just settling down after the massive upheaval of the Griffiths management revolution. It also poses the danger of spreading the narrow professionalisation and restrictive working practices that bedevil the health professions into community domiciliary and residential care-something that $\mathrm{Mr}$ Clarke may feel particularly sensitive about in view of his problems with the grading exercise for clinical nurses.

The Griffiths proposals could work well provided that there are tight financial controls and good monitoring of service plans for each care group. The mechanism of an intermediate agency to oversee transfer of responsibility to local authorities requires the least upheaval and could be the first step in separating the proper responsibility for medical and health care of central government from the provision of social and domestic care by the elected local authority.

Professor of Psychogeriatrics,

ELAINE MURPHY

United Medical Schools of Guy's and St Thomas's Hospitals,

Guy's Hospital,

London SE1 9RT

1 Griffiths R. Community care: agenda for action. London: HMSO, 1988.

2 Murphy E. Griffiths on community care: potentially disastrous. Br Med f 1988:296:876-7.

3 King's Fund Institute. Community care-reacting to Griffiths. London: King's Fund, 1988. (King's Fund Institure Briefing No 1)

\section{Autres pays, autres moeurs}

\section{Theories on why the French have less heart disease than the British}

Travel from Scotland to England and thence to France and you pass through countries displaying major contrasts in their mortality. ${ }^{2}$ Scotland has high mortality from all causes in both sexes; in women it is among the highest in the world. In 1983 Scotland had the highest age standardised mortality rates for coronary heart disease in the world for both men and women. ${ }^{3}$ In England and Wales mortality from all causes is lower for both men and women but high by international standards. In the world league table of deaths from coronary heart disease England and Wales are several places from the top. In France mortality from all causes in men is similar to that in England and Wales, although marginally lower. By contrast, Frenchwomen have an age standardised death rate that is only two thirds that of women in England and Wales. Mortality from coronary heart disease in men, according to the official statistics, is less than a third of that in England and Wales and a quarter of that in Scotland. In Frenchwomen mortality from coronary artery disease is one fifth that in women in England and Wales and one sixth that in Scottish women. ${ }^{2}$

Frenchmen do not live appreciably longer than Englishmen because, although their total mortality from circulatory disease is only half that of Englishmen, mortality from other causes is higher. Rates are lower for carcinoma of the bronchus but much higher for tumours of the mouth, oesophagus, and larynx. Among other noteworthy causes of increased mortality in Frenchmen are suicide, accidents, ill defined causes, and-most particularly-chronic liver disease (which includes cirrhosis) and digestive diseases. Frenchwomen, on the other hand, seem to have it both ways. Although they have an excess of deaths from liver disease, ill defined causes, accidents, and suicide these contribute only a few deaths. Deaths from cancer are much lower than among Englishwomen, even for the cancers in which Frenchmen show an excess. The low mortality from cancer and from cardiovascular disease results in the better life expectancy of Frenchwomen. ${ }^{2}$

Why do the French seem to have so much less coronary heart disease than the British? Is it really true, and if so does the fact that Frenchmen enjoy rich food disprove the idea that diet is important in coronary artery disease? Unfortunately, a national excess of disease is a greater spur to research than is a deficit. The most famous attempt to explain international variation in mortality from coronary heart disease - the seven countries study ${ }^{+}-$concluded that mortality was closely related to the average serum concentration of cholesterol in the population and to the intake of saturated fat but did not include any French cohorts. French researchers have, however, been attempting to answer some of these questions.

Mortality from coronary heart disease in France is higher in the north than in the south. There is a social class gradient, with less disease in the professional classes. ${ }^{5}$ The classic coronary risk factors that predict coronary heart disease in American and British studies also do so when applied prospectively to Frenchmen in the Paris prospective study, , $^{6-8}$ but disease occurs at a lower rate. Although there has been doubt in the past about the diagnoses given on death certificates in France, this is less true now. Most death certificates are specific, and researchers have totted up those with unsatisfactorily vague diagnoses that might have been coronary heart disease to work out what the mortality would be if they were. ${ }^{910}$ When this is done French mortality is similar to that of many southern European countries, which was also shown by the French registers of myocardial infarction in the 1970s. " Unlike in the Mediterranean countries that figure in the seven countries study, however, fat intake in France is not particularly low. ${ }^{910}$ There remains therefore a French paradox that has stimulated several hypotheses.

Frenchmen and women drink more wine than those in other countries; they eat more garlic and onions; the fat they consume contains more polyunsaturated essential fatty acids than that from Northern climes; and Frenchwomen insist on buying fresh food every day in the market and then cook vegetables very gently. Theories to explain the French paradox thus depend on protection from wine (it raises high density lipoprotein cholesterol concentration), garlic and onions (effect on clotting factors), ${ }^{12-14}$ polyunsaturated fatty acids (effect on clotting factors and function of platelets), ${ }^{15}$ and vitamins (protection from degradation of fats by free radicals to atherogenic products). ${ }^{16}$ Unfortunately, these dietary habits are so correlated that cross cultural studies have difficulty in teasing out what matters. The French paradox could, however, be of great interest if it leads to confirmation that there are foods that protect against coronary artery disease rather than cause it. 